\title{
Traditional Chinese Herbal Medicine for Epilepsy Treatment Should Be Administered According to the Seizure Type and Epileptic Syndrome
}

\author{
Lun Cai \\ Department of Encephalopathy, The First Affiliated Hospital of Guangxi University of Chinese Medicine, Guangxi University of \\ Chinese Medicine, Nanning, China \\ Email: zaozhi322@163.com
}

How to cite this paper: Cai, L. (2017) Traditional Chinese Herbal Medicine for Epilepsy Treatment Should Be Administered According to the Seizure Type and Epileptic Syndrome. Health, 9, 1211-1222. https://doi.org/10.4236/health.2017.98087

Received: August 7, 2017

Accepted: August 21, 2017

Published: August 24, 2017

Copyright $\odot 2017$ by author and Scientific Research Publishing Inc. This work is licensed under the Creative Commons Attribution International License (CC BY 4.0).

http://creativecommons.org/licenses/by/4.0/

\begin{abstract}
Traditional Chinese herbal medicine (TCHM) has long been used to treat epilepsy. Although many clinical trials and animal studies have seemingly demonstrated its effect, the question of whether TCHM is efficacious in epileptic patients has not been certified because of insufficient supportive evidence. This insufficient supportive evidence stems from the fact that most of the current studies regarding TCHM for epilepsy treatment are not designed according to the different seizure types and epileptic syndromes (STESs). Here, we explore the reasons why many studies have not considered the various STESs and explain how to treat epilepsy according to the pharmacological mechanism for different STESs and exploit the advantage of TCHM for epilepsy treatment. Then, we explain how we treat epilepsy using TCHM according to the different STESs and Bian Zheng Lun Zi.
\end{abstract}

\section{Keywords}

Epilepsy, Traditional Chinese Herbal Medicine, Seizure Type, Epileptic Syndromes, Epilepsy Classification

\section{Introduction}

Epilepsy is a wide-reaching and complex illness affecting more than 70 million people worldwide and can take on a variety of forms, patterns, and severities [1]. Despite the development of new antiepileptic drugs, $20 \%-30 \%$ of people with epilepsy remain refractory to treatment [2]. Furthermore, the adverse effects of antiepileptic drugs (AEDs) have a prevalence of up to 81.3\% [3]. Some adverse 
effects, such as suicide [4], cognitive dysfunction [5], Stevens-Johnson syndrome [6], serious endocrine disorders [7], and depression [8], are very serious. Therefore, finding other safe and effective drugs is an important future direction. In traditional Chinese medicine, traditional Chinese herbal medicines (TCHMs) have been used for centuries to treat seizures in China. These complex mixtures have been recognized as effective and safe medicaments for epilepsy treatment, not only for ancient societies but also for contemporary patients, from the mainland to overseas. However, there is insufficient supportive evidence to certify the effect of TCHM for epilepsy treatment, partly because the studies are not based on epilepsy classifications. A review of TCHM for epilepsy treatment has indicated that many TCHMs have only been examined in animal models for antiepileptic effects, without adequate evidence from controlled clinical trials, partly because the authors did not treat epilepsy according to an accurate epilepsy classification [9]. In an intervention review regarding TCHM for epilepsy, in all the eligible random controlled studies (see Table 1), three studies identified other seizure types except for GTCS. It is perplexing that, although normally speaking, epileptic syndrome is diagnosed based on the seizure types (myoclonic seizures, atonic seizures or absence are common seizure types of some epileptic syndromes), none of the epileptic syndromes were mentioned in these studies, even if we determined if the epilepsy was normally easy to be controlled by the epilepsy classification. Furthermore, according to the definition of "xianzheng" in Chinese Internal Medicine [10], myoclonic seizures, atonic seizures and absence seizures should be excluded from the "xianzheng" because the seizures are not similar to the symptoms described in the textbook. The review reflected two problems: First, none of the studies verified the effect of TCHM for epilepsy treatment according to the epilepsy classification. Second, the definition of "xianzheng" in Chinese Internal Medicine is limited because other seizure types and epileptic syndromes (STESs) are not included. A similar situation is seen in the subsequent, new review [11]. The current studies demonstrate that we should attach importance to using TCHM for epilepsy treatment according to the different STESs.

Table 1. Seizure types and epileptic syndrome of TCMH for epilepsy treatments in a review (Li Q, et al., 2009).

\begin{tabular}{cccc}
\hline \multicolumn{1}{c}{ Studies } & Seizure type & $\begin{array}{c}\text { Epileptic } \\
\text { syndrome }\end{array}$ & Diagnose from Chinese medicine \\
\hline Liu 1994a & primary GTCS & Not mentioned & "wind phlegm types" of "xian zheng" in TCM \\
Song 2001 & $\begin{array}{c}\text { GTCS, absence, simple partial seizure, complex partial seizure, } \\
\text { myoclonic seizures, atonic seizures }\end{array}$ & Not mentioned & "xian zheng" in TCM \\
Tian 2006 & GTCS, absence, simple partial seizure, complex partial seizure & Not mentioned & "xian zheng" in TCM \\
Xiang 1998 & primary GTCS & Not mentioned & "xian zheng" in TCM \\
Xin 1999 & GTCS, STCS & Not mentioned & "xian zheng" in TCM \\
\hline
\end{tabular}

Note: GTCS = generalized tonic-clonic seizure; STCS = secondary generalized tonic-clonic seizure; TCHM = traditional Chinese herbal medicine; TCM = traditional Chinese medicine. 


\section{Epilepsy Treatment Should Be Based on the Different Seizure Types and Epileptic Syndromes}

Epilepsy classification is very complex; based on the clinical manifestation and the EEG features, there are different epilepsy types and epileptic syndromes even if the classification system is not perfect. Based on the etiology, epilepsy includes idiopathic, symptomatic, cryptogenic epilepsy and epileptic syndrome. Selecting AEDs according to the different STESs is a basic principle of epilepsy treatment. Drugs for epilepsy treatment are based on different STESs because of the different pharmacological mechanisms. In the antiepileptic guidelines [12], drugs are listed as a first-line choice, second-line choice and additive therapy for different STESs according to evidence-based medicine. Drugs that exacerbate seizures would be ruled out from the list. Taking absence seizures for example, according to the antiepileptic guidelines, valproate and ethosuximide are the first-line drugs, Lamotrigine is the second-line drug, and clonazepam, topiramate and levetiracetam are the additive drugs. Other sodium ion channel blockers, such as carbamazepine, oxcarbazepine, and vigabatrin, are banned for use for absence seizures. Treating epilepsy according to the different epilepsy classifications became our basic principle.

\section{Limits of the Definition of "Xianzheng" in Chinese Internal Medicine Influences the Cognition of the Epilepsy Classifications}

Epilepsy in traditional Chinese medicine has had a long history. A review has reported that most seizure types were only confined to generalized tonic-clonic seizures (GTCS) by Huang Di Nei Ching, other subsequent publications [13], and in the description in the latest version textbook for undergraduate, Chinese Internal Medicine; "xianzheng" was described as a "sudden loss of consciousness, upward staring eyes, drool foaming at the mouth, tonic convulsion, bawl and squall" [10]. It is undeniable that GTCS was the most common and the most easily observed seizure type. Therefore, another study also reported that no other STESs were identified in Chinese Internal Medicine [14]. Indeed, other STESs were also seemingly described. Some epileptic syndromes or GTCS were described in the literature when epilepsy was described as "dianzheng", "kuangzheng" or "xianzheng" before the Ming dynasty [15], such as the description in Qian Jin Yao Fang, written thus by Sun Simiao: The feng dian was manifested by tonic convulsion, open mouth and eyes, frothing at the mouth or crying out, or losing consciousness [16]. In the same book, the "xianzheng" was described as follows: When the baby was in his mother's uterus, a cold wind intruded into the mother's uterus, and hurt the baby's Zang and Fu. When the baby was born, pathogenic factors remained in the baby's abdomen. The pathogenic factors and vital qi struggled together in the baby's abdomen, and thus the baby stretched its body, breathed hard and cried out [16]. This was seemingly an episode of Panayiotopoulos syndrome. After the Ming dynasty, "dianzheng" referred to psychosis 
without excitation, "kuangzheng" referred to psychosis with excitation, and "xianzheng" referred to convulsions [17]. In addition to GTCS, other STESs have been described in the publications, such as complex-partial seizures that originate from temporal lobe epilepsy (TLE) [17], Panayiotopoulos syndrome [18], absence seizures [19], status epilepticus [19], febrile seizures [20], and likely-benign epilepsy with centro-temporal spikes [20] (see Table 2).

In addition to the most common GTCS, other STESs are not described in the textbook Chinese Internal Medicine because of the atypical manifestation. As a notebook published by a professional publishing house, the limits of "xianzheng" described in Chinese Internal Medicine influenced many physicians and researchers who have an interest in Chinese medicine [14], which further influenced the clinical therapeutics and related study. Therefore, in the future, the definition of "xianzheng" in the Chinese Internal Medicine textbook should be modified according to the description in the ancient publications and the scientific epilepsy classification [14].

\section{Limits to the Understanding of Epilepsy Knowledge Influenced the Cognition of Epilepsy Classifications}

There is another reason that studies are not based on the STES. Data from

Table 2. Description of the seizure type and epileptic syndrome in ancient Chinese publications.

\begin{tabular}{|c|c|c|c|c|}
\hline Dynasty & Author & Book & Description & $\begin{array}{l}\text { Probable seizure type and } \\
\text { epileptic syndrome }\end{array}$ \\
\hline Sui [16] & $\begin{array}{c}\text { Chao } \\
\text { Yuanfang }\end{array}$ & $\begin{array}{l}\text { Zhu Bing } \\
\text { Yuan } \\
\text { Hou Lun }\end{array}$ & $\begin{array}{l}\text { When the baby is in his mother's uterus, a cold wind intrudes into the } \\
\text { mother's uterus, and harms the baby's Zang and Fu. When the baby is } \\
\text { born, pathogenic factors remain in the baby's abdomen. The pathogenic } \\
\text { factors and vital qi struggle together in the baby's abdomen, and thus the } \\
\text { baby stretches its body, breathes hard and cries out. }\end{array}$ & $\begin{array}{l}\text { Panayiotopoulos } \\
\text { syndrome }\end{array}$ \\
\hline $\begin{array}{c}\text { Ming } \\
{[18]}\end{array}$ & Wanquan & $\begin{array}{l}\text { You Ke } \\
\text { Fa Hui }\end{array}$ & $\begin{array}{l}\text { The patients who are sick from Nei Diao originated from the cold, } \\
\text { intruding Gan, which further contributes to abdominal pain and crying } \\
\text { out. The two eyes look forward steadily, but there is no tonic convulsion. }\end{array}$ & $\begin{array}{l}\text { Panayiotopoulos } \\
\text { syndrome }\end{array}$ \\
\hline $\begin{array}{c}\text { Ming } \\
{[17]}\end{array}$ & $\begin{array}{l}\text { Wang } \\
\text { Kentang }\end{array}$ & $\begin{array}{l}\text { Zheng } \\
\text { Zhi Zhun } \\
\text { Sheng }\end{array}$ & $\begin{array}{l}\text { The patient suddenly sees a ghost-like subject, and smells an awful odor, } \\
\text { falling to the ground with both fists clenched. The limbs become cold, } \\
\text { and then the patient becomes unconscious. }\end{array}$ & $\begin{array}{l}\text { complex-partial seizure } \\
\text { that originated from } \\
\text { temporal lobe } \\
\text { epilepsy(TLE) }\end{array}$ \\
\hline $\begin{array}{l}\text { Ming } \\
{[19]}\end{array}$ & Fangxian & $\begin{array}{l}\text { Qi Xiao } \\
\text { Liang } \\
\text { Fang }\end{array}$ & $\begin{array}{l}\text { Epilepsy caused by terror: one or two eyes are disabled. The patient } \\
\text { cannot see things clearly or cannot see anything, or there is writhing, or a } \\
\text { twisted mouth, or a shaking head. }\end{array}$ & Absence seizure \\
\hline $\begin{array}{l}\text { Qing } \\
{[19]}\end{array}$ & $\begin{array}{l}\text { Shen } \\
\text { Jin'ao }\end{array}$ & $\begin{array}{l}\text { Shen Shi } \\
\text { Zun } \\
\text { Sheng } \\
\text { Shu }\end{array}$ & $\begin{array}{l}\text { During the epileptic attacks, the patient makes unusual noises, and froths } \\
\text { at the mouth. When the patient is about to awaken, the epileptic attacks } \\
\text { begin again, and the cycle occurs again and again and never stops... }\end{array}$ & status epilepticus \\
\hline Sui [20] & $\begin{array}{l}\text { Chao } \\
\text { Yuanfang }\end{array}$ & $\begin{array}{l}\text { Zhu Bing } \\
\text { Yuan } \\
\text { Hou Lun }\end{array}$ & $\begin{array}{l}\text { The high temperature persists, babies get acute infantile convulsion or } \\
\text { seizure when is serious }\end{array}$ & febrile seizure \\
\hline Sui [20] & $\begin{array}{l}\text { Chao } \\
\text { Yuanfang }\end{array}$ & $\begin{array}{c}\text { Zhu Bing } \\
\text { Yuan } \\
\text { Hou Lun }\end{array}$ & $\begin{array}{l}\text { Shaking head, playing with the tongue, or tonic convulsion when } \\
\text { sleeping, along with gritted teeth }\end{array}$ & $\begin{array}{l}\text { benign epilepsy with } \\
\text { centro-temporal spikes }\end{array}$ \\
\hline
\end{tabular}


Clinical Guidelines for the Diagnosis and Treatment of Epilepsy, which was written by the Chinese Association against Epilepsy, revealed that some general practitioners are unfamiliar with epilepsy classification, diagnosis and treatment. They might consider partial seizures to be generalized seizures, might not know about the epileptic syndrome, might regard nonepileptic seizures as epileptic seizures, or might prescribe many types of AEDs for patients in a blinded fashion [12]. A study has investigated the epilepsy knowledge level of medical neurologists in China. The average epilepsy mark fails to pass the standard level even if the doctors are the senior attendings or have received a post-graduate educational background at their hospital. The researchers also found that the score on the item of epilepsy treatment is lower than the item of epilepsy diagnosis, although the doctors come from tertiary hospitals regarded as the best hospitals in China [21]. Treating epilepsy according to the different STESs is the basis of epilepsy treatment. The study reflects the problem that the physicians' treatment of epilepsy was not based on the epilepsy classification because they were short on knowledge regarding epilepsy diagnosis and treatment, although epilepsy was considered the main disease in the neurology department at a hospital.

The study indirectly reflects our physicians' level of epilepsy knowledge, which further influenced the cognition of epilepsy classification, and it advised that further education should be conducted to improve the doctors' knowledge level regarding epilepsy diagnosis and treatment. Furthermore, senior attendings or epilepsy specialists should strengthen the guidance of epilepsy knowledge for resident doctors [21]. In addition to these measures, many projects, such as "Against epilepsy in the western region," which was sponsored by the Chinese Association against Epilepsy, are conducted to improve the primary doctors' level of epilepsy diagnosis and treatment by gratuitous treatment and a series of epilepsy lectures [12].

\section{Treating Epilepsy According to the Different STESs to Exploit the Advantages of TCHM for Epilepsy Treatment}

Treating epilepsy according to the different STESs from clinical trials and animal research is the first step through which we certify the effects of TCHM, and it is the pathway of evidence-based medicine for TCHM for epilepsy. It is gratifying that some clinical trials and animal studies are heading in this direction. Furthermore, we should redefine the specific target of TCHM for epilepsy under the condition that many doctors and patients regard traditional Chinese medicine as complementary and alternative medicines (CAMs) [22] [23]. The advantage of TCHM for epilepsy treatment has not been verified partly because the studies did not diagnose and treat according to the epilepsy classification [9]. In fact, TCHM was not only a CAM for refractory epilepsy and epileptic syndrome [24] but also an initial monotherapy choice for many easily controlled epilepsy and epileptic syndrome (see Table 3). According to previous studies, our experience and the current epilepsy classification, (1) in clinical trials, TCHM may be used 
Table 3. TCHM for different seizure types and epileptic syndrome.

\begin{tabular}{|c|c|c|c|}
\hline Considerable initial monotherapy & Tentatively initial monotherapy & Additive treatment & $\begin{array}{l}\text { Prophylactic } \\
\text { treatment }\end{array}$ \\
\hline $20 \%-30 \%$ of the populations & $30 \%-40 \%$ of the populations & $30 \%-50 \%$ of the populations & $\begin{array}{c}2 \%-15 \% \text { of the } \\
\text { populations }\end{array}$ \\
\hline $\begin{array}{c}\text { benign epilepsy and epileptic } \\
\text { syndrome }\end{array}$ & $\begin{array}{l}\text { idiopathic epilepsy and epileptic } \\
\text { syndrome, some partial epilepsy }\end{array}$ & $\begin{array}{l}\text { many partial epilepsies (symptomatic or } \\
\text { cryptogenic) and all the epileptic encephalopathies }\end{array}$ & febrile seizures \\
\hline $\begin{array}{l}\text { BNE, BECTS, Panayiotopoulos } \\
\text { syndrome, BMEI and others }\end{array}$ & $\begin{array}{l}\text { CAE, JME, EGTSO, easy } \\
\text { controlled partial epilepsy }\end{array}$ & $\begin{array}{l}\text { Symptomatic partial epilepsy, cryptogenic partial } \\
\text { epilepsy, epileptic encephalopathy }\end{array}$ & febrile seizures \\
\hline
\end{tabular}

Note. $\mathrm{TCHM}=$ traditional Chinese herbal medicine; $\mathrm{BNE}=$ benign neonatal epilepsy; BECTS = benign epilepsy with centro-temporal spikes; $\mathrm{BMEI}=$ benign myoclonic epilepsy in infancy; CAE = childhood absence epilepsy; JME = juvenile myoclonic epilepsy; EGTSO = epilepsy with generalized tonic-seizures only.

as an initial monotherapy in newly diagnosed benign epilepsy and epileptic syndrome; patients with benign epilepsy make up $20 \%-30 \%$ of the entire population of epileptic patients, and some benign epilepsies are idiopathic epilepsies [25]. These benign epilepsies include benign neonatal epilepsy, benign epilepsy with centro-temporal spikes (BECTS), benign childhood occipital epilepsy ( $\mathrm{Pa}$ nayiotopoulos syndrome), benign myoclonic epilepsy in infancy, etc. Generally, a large number of epileptic patients with benign epilepsy always have a natural history or can be easily controlled with a small dose of AEDs [25]; consequently, it is possible for traditional Chinese herbal medicine to be used as monotherapy for epilepsy and epileptic syndrome. Regrettably, there is no related report about TCHM for benign epilepsy and epileptic syndrome. Our team had found that ilepcimide tablets, an extract from pepper that has been certified for tonic-clonic seizures [26], and Chaihu shugan decoction, a self-made compound recipe of Chinese herbal medicine that has been certified for temporal lobe epilepsy in rats [27] [28], were effective antiepileptic drugs as initial monotherapy for BECTs; the data will be published in the future, even if coming from small sample trials. (2) Compared to benign epilepsy, we can also attempt to use TCHM as an initial monotherapy for some idiopathic epilepsy and epileptic syndromes and for some partial epilepsies because patients might be seizure free without AEDs or because some patients with these epilepsy and epileptic syndromes can be easily controlled with small doses of AEDs [25]. These epilepsy and epileptic syndromes account for $30 \%-40 \%$ of the epileptic patients and include childhood absence epilepsy, juvenile myoclonic epilepsy, epilepsy with generalized tonic-seizures only and some easily controlled partial epilepsies [12]. In fact, we should try to use TCHM as initial monotherapy for these epilepsy and epileptic syndromes first; if the seizures are uncontrolled by TCHM alone, TCHM would be replaced by AEDs or used as an additive drug to reduce the dose of AEDs and adverse effects. Only one study has reported that Anshen Dingxian Tang is more effective than valproic acid in treating childhood absence seizures even if the adverse events and the epileptic syndrome are not mentioned [29]. As we know, typical absence seizure is the seizure type of childhood absence epilepsy and juvenile 
absence epilepsy, but in the study, no epileptic syndrome was mentioned. There are many studies about TCHM alone for partial epilepsy, but few studies have mentioned the epilepsy types [11]. It is established that partial epilepsy can be divided into familial partial epilepsy, symptomatic epilepsy or cryptogenic epilepsy; moreover, some familiar partial epilepsies are benign. The prognoses of other partial epilepsies are different, but no accurate partial epilepsy classifications are mentioned. (3) Many partial epilepsies (symptomatic or cryptogenic) and all the epileptic encephalopathies, such as symptomatic West syndrome, symptomatic Lennox-Gastaut syndrome and other refractory epilepsies, are difficult to be controlled by AEDs even if the combination of many AEDs are used [30] [31]. Currently, TCHM is used as an additive treatment for these refractory epilepsies to increase the therapeutic effects or reduce the adverse effects. A study reported that Dianxianning, an oral Chinese Traditional Patent Medicine, is more effective than using chemical medicine alone to control refractory epilepsy, but the epilepsy classification was not mentioned [32]. Another study of Chaibei Zhixian Decoction for refractory epilepsy with complex partial seizures also demonstrated it was an effective and safe drug to reduce seizure frequency when compared to AEDs alone [33]. Other studies reported that asiatic acid [34], a triterpenoid derived from Centella asiatica, and rutin [35], a bioflavonoid derived from many TCHMs, were used to alleviate the cognitive impairments caused by AEDs in animals. The review regarding TCHM as an additive treatment for epilepsy demonstrated a similar problem in that many of the studies did not identify the epilepsy classification or have a credible study design [11]. Thus, it is early to completely accept using TCHM as a monotherapy for patients with refractory epilepsy. It is a relief to see that some specialists have begun to certify the effect of additive TCHM for epilepsy treatment according to evidence-based medicine study designs, such as "Chaibei Zhixian Decoction for Complex Partial Seizure of intractable Epilepsy: a Randomized, Double-blind, Placebo-controlled trial (ChiCTR-IPR-16008775, will be completed in 2020)". (4) Furthermore, febrile seizures are the most common childhood seizure and have shown a five-fold increased risk of developing unprovoked seizures compared with children with no febrile seizures [36]. Although the risk factors for developing epilepsy are not linked to the recurrence of febrile seizures, the studies show that children with recurrent or prolonged febrile seizures may be at increased risk for recognition memory impairment. Furthermore, febrile seizures are usually a very frightening experience for parents. Given the usually benign nature of febrile seizures and the high risk of adverse effects with medications, there currently is no role for prophylactic antiepileptic drugs in preventing recurrent febrile seizures [37]. Preventing and curing the disease is the main method and means of traditional Chinese medicine. "Prevention before disease onset and preventing disease from exacerbating" is the basic principle. A pilot, random, controlled study demonstrated that Lingyang-ganmao-koufu-ye is an effective and safe drug for preventing febrile seizures compared to diazepam. 
"Adjustment of constitution" was the systematic theory of the constitution of Chinese medicine [38]. In addition to preventing seizures during fevers, it is necessary to adjust the constitution to avoid getting fevers. One study has reported that TCMH may improve immunity through a constitution adjustment to avoid infection [39].

\section{Selecting the Right TCHM for Different STESs According to the Pharmacological Mechanism}

Selecting AEDs according to the pharmacological mechanism for different STESs is a basic principle of epilepsy treatment. Taking some TCMHs for example, the antiepileptic effect of some TCMHs or the ingredients of TCMH are similar to those of sodium channels blockers, such as saikosaponin, the primary active constituent derived from $B$. chinenses (the principal ingredient of the Chaihu shugan decoction), which had been reported to inhibit the N-methyl-D-aspartate (NMDA) receptor current and INaP [40]. Ilepcimide tablets, an extract from pepper, have been reported to inhabit the sodium current also [41]. Based on the epilepsy classification and treatment, sodium channels blockers may exacerbate absence seizures and myoclonic seizures; thus, we should avoid using these TCMHs to treat epileptic syndromes that include absence seizures or myoclonic seizures. Regrettably, there are no related studies. Furthermore, as sodium channels blockers were the first-line drugs for partial epilepsy, we could use saikosaponin and Ilepcimide tablets as initial monotherapy for idiopathic partial epilepsy or easily controlled partial epilepsy. A retrospective study of Ilepcimide tablets as monotherapy for childhood partial seizures demonstrated that the seizure-free proportion, the effective rates (seizure frequency reduced by at least $50 \%$ ) of the 6-month treatment period in the 2 - 5 year group are $48.15 \%$ and $77.78 \%$ and in the 5 - 15 year group is $51.28 \%$ and $79.49 \%$. The proportion of adverse effects in the $2-5$ year group is $4.55 \%$ and in the $5-15$ year group is $10.61 \%$; no serious adverse effects occurred [42]. Unfortunately, no epilepsy syndrome was mentioned, even if there is a difference between the effective rate of benign partial epilepsy and symptomatic epilepsy. Baicalin, the primary active ingredient of Huangqin, has been reported to have a similar antiepileptic effect to that of benzodiazepines by acting on the $\gamma$-aminobutyric acid type $A$ $\left(\mathrm{GABA}_{\mathrm{A}}\right)$ receptor [43] [44]. Thus, we can attempt to use baicalin instead of benzodiazepines if the patient cannot tolerate the benzodiazepine side effects. Of course, the antiepileptic effects of a single drug are complex, and there are many pharmacological mechanisms even if it is a single drug. There are more active ingredients in a single TCMH, and the complexity of a single TCMH is more than that of a single western drug. Furthermore, combination therapy is a fundamental principle of Chinese medicine. Normally speaking, Chinese herbal medicine prescription is thought to conform to the ancient principle known as jun chen zuo shi. Jun establishes a major ingredient, and other mixtures help the major ingredient to maximize the therapeutic efficacy and ameliorate the potential 
adverse effects. The pharmacological mechanism of many mixed TCMH is the most complex one. However, selecting the right TCMH according to different pharmacological mechanisms for different STESs is the principle that we should follow.

\section{Combinating Bian Zheng Lun Zi for Epilepsy Treatment}

Bian Zheng Lun $\mathrm{Zi}$ is a principal of traditional Chinese medicine, which suggests that the doctor treat epilepsy using different Chinese herbal medicines according to the different syndromes ("syndrome" is a professional term in traditional Chinese medicine; it is a recap of pathogenesis and etiology in a special phase and differs from epileptic syndrome) even if the STESs are identical [15]. Seemingly, there is a difference between Bian Zheng Lun Zi and treating epilepsy based on STESs although the two all attach importance to individualized treatment. Bian Zheng Lun $\mathrm{Zi}$ advises the doctor to collect the signs of a patient by Wang Wen Wen Qie; one's sign reflects his inner characteristic of the "syndrome". Different STESs also reflect the different features of epilepsy. When the clinical treatment is complete, all can be based on each other when treating patients, and we can use the different prescription when we treat the same STES, we could also use the similar prescription when we treat the different STES.

\section{Conclusion}

Treating epilepsy has not been based on the accurate epilepsy classification, and this is the primary reason that current evidence on the effect of TCMH for epilepsy treatment is insufficient. The limits of the textbook Chinese Internal Medicine should be modified, and the level of epilepsy knowledge of physicians and researchers should be improved in favor of their conducting clinical trials and studies according to the different pharmacological mechanisms and Bian Zheng Lun Zi for different STESs.

\section{Acknowledgements}

We thank Elsevier for the professional English language editing.

\section{Conflict of Interest}

The authors declare that they have no conflicts of interest.

\section{References}

[1] Singh, A. and Trevick, S. (2016) The Epidemiology of Global Epilepsy. Neurologic Clinics, 34, 837-847. https://doi.org/10.1016/j.ncl.2016.06.015

[2] Dalic, L. and Cook, M.J. (2016) Managing Drug-Resistant Epilepsy: Challenges and Solutions. Neuropsychiatric Disease and Treatment, 12, 2605-2616. https://doi.org/10.2147/NDT.S84852

[3] Zaccara, G., Giovannelli, F., Franco, V., Cincotta, M., Tramacere, L. and Verrotti, A. (2014) Adverse Events, Placebo and Nocebo Effects in Placebo-Treated Paediatric 
Patients with Refractory Focal Epilepsies. Analysis of Double-Blind Studies. Epilepsy Research, 108, 1685-1693. https://doi.org/10.1016/j.eplepsyres.2014.09.015

[4] Hesdorffer, D.C. and Kanner, A.M. (2009) The FDA Alert on Suicidality and Antiepileptic Drugs: Fire or False Alarm? Epilepsia, 50, 978-986.

https://doi.org/10.1111/j.1528-1167.2009.02012.x

[5] Park, S.P. and Kwon, S.H. (2008) Cognitive Effects of Antiepileptic Drugs. Journal of clinical neurology, 4, 99-106. https://doi.org/10.3988/jcn.2008.4.3.99

[6] Aggarwal, R., Sharma, M., Modi, M., Garg, V.K. and Salaria, M. (2014) HLA-B* 1502 Is Associated with Carbamazepine Induced Stevens-Johnson Syndrome in North Indian Population. Human Immunology, 75, 1120-1122. https://doi.org/10.1016/j.humimm.2014.09.022

[7] McIntyre, R.S., Mancini, D.A., McCann, S., Srinivasan, J. and Kennedy, S.H. (2003) Valproate, Bipolar Disorder and Polycystic Ovarian Syndrome. Bipolar Disorders, 5, 28-35. https://doi.org/10.1034/j.1399-5618.2003.00009.x

[8] Kanner, A.M., Barry, J.J., Gilliam, F., Hermann, B. and Meador, K.J. (2012) Depressive and Anxiety Disorders in Epilepsy: Do They Differ in Their Potential to Worsen Common Antiepileptic Drug-Related Adverse Events? Epilepsia, 53, 1104-1108. https://doi.org/10.1111/j.1528-1167.2012.03488.x

[9] Li, Q., Chen, X., He, L. and Zhou, D. (2009) Traditional Chinese Medicine for Epilepsy. The Cochrane Database of Systematic Reviews, CD006454.

[10] Wu, M. and Wang, X. (2012)Chinese Internal Medicine. China Press of Traditional Chinese Medicine, Beijing.

[11] Nie, L., Zhang, Q., Wang, X., Sun, J., Zhang, Y. and Liu, J. (2015) Systematic Review of Adult Epilepsy Treated by Chinese Herbal Medicine. Journal of Emergency in Traditional Chinese Medicine, 569-572.

[12] Epilepsy, C.A.A. (2015) Clinical Guidelines for the Diagnosis and Treatment of Epilepsy. People's Medical Publishing House, Beijing.

[13] Xiao, F., Yan, B., Chen, L. and Zhou, D. (2015) Review of the Use of Botanicals for Epilepsy in Complementary Medical Systems-Traditional Chinese Medicine. Epilepsy \& Behavior. E\&B, 52, 281-289. https://doi.org/10.1016/j.yebeh.2015.04.050

[14] Liu, J.M. and Jiang, T. (2006) [Pondering on the Diagnosis and Treatment Criteria for Syndromes of Epilepsy in Traditional Chinese Medicine]. Zhong xi yi jie he xue bao = Journal of Chinese Integrative Medicine, 4, 572-574. https://doi.org/10.3736/jcim20060605

[15] Lai, C.W. and Lai, Y.H. (1991) History of Epilepsy in Chinese Traditional Medicine. Epilepsia, 32, 299-302. https://doi.org/10.1111/j.1528-1157.1991.tb04655.x

[16] Jiang, D. and Ning, S. (2008) Exploration on the Origin and Development of the Insanity. Chinese Archives of Traditional Chinese Medicine, 2544-2547.

[17] Lee, T.M., Yang, S.H. and Ng, P.K. (2001) Epilepsy in Chinese Culture. The American journal of Chinese medicine, 29, 181-184. https://doi.org/10.1142/S0192415X01000204

[18] Zhang, H. (1992) Traditional Chinese Medicine for Special Types of Epilepsy. Journal of Traditional Chinese Medicine, 33, 13-14.

[19] Yu, C. (1982) The Cognition and Treatment on Epilepsy in Traditional Chinese Medicine. Shandong Journal of Traditional Chinese Medicine, 89-91.

[20] Liu, Z., Zou, W., An, Y., Wang, H. and Li, Y. (2016) Analysis on the Origin and Development of Epilepsy. Journal of Shandong University of Traditional Chinese Medicine, 360-362. 
[21] Zhou, Y., Liu, M., Ding, C., Zhao, Y., Li, Z. and Liang, W. (2007) Investigation among Neurological Doctors about the Epileptic Knowledge Grasping and the Affecting Factors. Chinese General Practice, 679-681.

[22] Chen, C., Chong, Y.J., Hie, S.L., Sultana, R., Lee, S.H., Chan, W.S., Chan, S.Y. and Cheong, H.H. (2016) Complementary and Alternative Medicines Use among Pediatric Patients with Epilepsy in a Multiethnic Community. Epilepsy \& Behavior. E\&B, 60, 68-74. https://doi.org/10.1016/j.yebeh.2016.04.008

[23] Kuan, Y.C., Yen, D.J., Yiu, C.H., Lin, Y.Y., Kwan, S.Y., Chen, C., Chou, C.C. and Yu, H.Y. (2011) Treatment-Seeking Behavior of People with Epilepsy in Taiwan: A Preliminary Study. Epilepsy \& Behavior. E\&B, 22, 308-312.

https://doi.org/10.1016/j.yebeh.2011.06.034

[24] Engel, J. (2014) Approaches to Refractory Epilepsy. Annals of Indian Academy of Neurology, 17, 12-17. https://doi.org/10.4103/0972-2327.128644

[25] Gomez-Alonso, J. and Bellas-Lamas, P. (2011) [The New International League Against Epilepsy (ILAE) Classification of Epilepsies: A Step in the Wrong Direction?]. Revista de Neurologia, 52, 541-547.

[26] Wang, L., Zhao, D.Y., Zhang, Z.H., Liu, C.S., Lin, Q., Hu, S.X., Wu, X.R., Zuo, Q.H., Zhang, Y.Y. and Pei, Y.Q. (1989) Double-Blind Crossover Controlled Study on Antiepilepsirine. Chinese Medical Journal, 102, 79-85.

[27] Yu, Y.H., Xie, W. and Zhao, Y.Y. (2013) [Effects of Heterotherapy for Homopathy on the Metabolism Path of Glutamate in the Pentylenetetrazol-Kindled Seizure Rats' Hippocampus]. Zhongguo Zhong xi yi jie he za zhi Zhongguo Zhongxiyi jiehe zazhi $=$ Chinese journal of integrated traditional and Western medicine / Zhongguo Zhong xi yi jie he xue hui, Zhongguo Zhong yi yan jiu yuan zhu ban, 33, 95-99.

[28] Yu, Y., Xie, W. and Wang, C. (2015) Chaihushugan Decoction Exerts Antiepileptic Effects by Increasing Hippocampal Glutamate Metabolism in Pentylenetetrazole-Kindled Rats. Journal of traditional Chinese Medicine $=$ Chung i tsa chih ying wen pan / sponsored by All-China Association of Traditional Chinese Medicine, Academy of Traditional Chinese Medicine, 35, 659-665. https://doi.org/10.1016/S0254-6272(15)30156-4

[29] Yang, X., Wang, Y. and Sun, J. (2015) The Effect of Anshen-Dingxian-Tang Treat Children with Abscence Seizure. Guiding Journal of Traditional Chinese Medicine and Pharmacy, 69-71.

[30] Shbarou, R. (2016) Current Treatment Options for Early-Onset Pediatric Epileptic Encephalopathies. Current Treatment Options in Neurology, 18, 44. https://doi.org/10.1007/s11940-016-0428-z

[31] Leong, C., Mamdani, M.M., Gomes, T., Juurlink, D.N., Macdonald, E.M. and Yogendran, M. (2016) Antiepileptic Use for Epilepsy and Nonepilepsy Disorders: A Population-Based Study (1998-2013). Neurology, 86, 939-946. https://doi.org/10.1212/WNL.0000000000002446

[32] He, L., Wen, T., Yan, S., Li, R., Liu, Z., Ren, H., Liu, J., Zhang, F., Wu, J. and Liu, J. (2011) Reevaluation of the Effect of Dianxianning on Seizure Rate of Refractory Epilepsy as Additive Treatment in Clinical Practice. Frontiers of Medicine, 5, 229-234. https://doi.org/10.1007/s11684-011-0139-5

[33] Nie, L., Yan, Z., Zhang, Q., Wang, X., Wang, Y., Sun, J., Zhang, Y. and Liu, J. (2015) Clinical Study of the Combination of Chaibei Zhixian Decoction with Anti-Epilepsy Drugs in the Treatment of Intractable Epilepsy Complex Partial Seizures. Global Traditional Chinese Medicine, 8, 13-18. 
[34] Umka Welbat, J., Sirichoat, A., Chaijaroonkhanarak, W., Prachaney, P., Pannangrong, W., Pakdeechote, P., Sripanidkulchai, B. and Wigmore, P. (2016) Asiatic Acid Prevents the Deleterious Effects of Valproic Acid on Cognition and Hippocampal Cell Proliferation and Survival. Nutrients, 8.

[35] Dubey, S., Ganeshpurkar, A., Bansal, D. and Dubey, N. (2015) Protective Effect of Rutin on Impairment of Cognitive Functions of Due to Antiepileptic Drugs on Zebrafish Model. Indian Journal of Pharmacology, 47, 86-89. https://doi.org/10.4103/0253-7613.150357

[36] Annegers, J.F., Hauser, W.A., Shirts, S.B. and Kurland, L.T. (1987) Factors Prognostic of Unprovoked Seizures after Febrile Convulsions. The New England Journal of Medicine, 316, 493-498. https://doi.org/10.1056/NEJM198702263160901

[37] Patel, N., Ram, D., Swiderska, N., Mewasingh, L.D., Newton, R.W. and Offringa, M. (2015) Febrile Seizures. BMJ, 351, h4240. https://doi.org/10.1136/bmj.h4240

[38] Wang, J., Wang, T., Li, Y.S., Zheng, Y.F., Li, L.R. and Wang, Q. (2015) Research on Constitution of Chinese Medicine and Implementation of Translational Medicine. Chinese Journal of Integrative Medicine, 21, 389-393. https://doi.org/10.1007/s11655-014-2019-8

[39] Zhang, J., Liang, W., Hong, J. and Kuang, L. (2016) Study on Shuang Ping San in Prevention of Children with Febrile Seizure. China Health Standard Management, 131-133.

[40] Yu, Y.H., Xie, W., Bao, Y., Li, H.M., Hu, S.J. and Xing, J.L. (2012) Saikosaponin a Mediates the Anticonvulsant Properties in the HNC Models of AE and SE by Inhibiting NMDA Receptor Current and Persistent Sodium Current. PloS One, 7, e50694. https://doi.org/10.1371/journal.pone.0050694

[41] Zeng, Y. (2011) Interaction of the Antiepileptic Drug Ilepcimide with Na+ Channels in Mice Hippocampal Neuronse. Guangzhou Medical College, Guangzhou, 1-69.

[42] Wang, Z., Yang, L., Zhang, S. and Yang, L. (2012) Study on Clinical Efficacy and Safety of Ilepcimide Monotherapy for Treatment of Children with Partial Seizures of Epilepsy. Maternal and Child Health Care of China, 5304-5307.

[43] de Carvalho, R.S., Duarte, F.S. and de Lima, T.C. (2011) Involvement of GABAergic Non-Benzodiazepine Sites in the Anxiolytic-Like and Sedative Effects of the Flavonoid Baicalein in Mice. Behavioural Brain Research, 221, 75-82. https://doi.org/10.1016/j.bbr.2011.02.038

[44] Yoon, S.Y., dela Pena, I.C., Shin, C.Y., Son, K.H., Lee, Y.S., Ryu, J.H., Cheong, J.H. and Ko, K.H. (2011) Convulsion-Related Activities of Scutellaria Flavones Are Related to the 5,7-Dihydroxyl Structures. European journal of pharmacology, 659, 155-160. https://doi.org/10.1016/j.ejphar.2011.03.012 
Submit or recommend next manuscript to SCIRP and we will provide best service for you:

Accepting pre-submission inquiries through Email, Facebook, LinkedIn, Twitter, etc. A wide selection of journals (inclusive of 9 subjects, more than 200 journals)

Providing 24-hour high-quality service

User-friendly online submission system

Fair and swift peer-review system

Efficient typesetting and proofreading procedure

Display of the result of downloads and visits, as well as the number of cited articles Maximum dissemination of your research work

Submit your manuscript at: http://papersubmission.scirp.org/

Or contact health@scirp.org 